\title{
El sentido de la vida: el caso de Bartolomé de las Casas*
}

Fecha de entrega: 7 de diciembre de 2016

Fecha de evaluación: 16 de febrero de 2017

Fecha de aprobación: 20 de abril de 2017

\author{
José Wilmar Pino Montoya*
}

\section{Resumen}

Este artículo realiza una reflexión del sentido de la vida; la vida de Bartolomé de las Casas. En primer lugar, se centra la atención en los comienzos de su vida. Posteriormente se analiza el momento denominado las "tres conversiones". Las mismas que despertaron múltiples críticas y contradicciones. La primera de estas transformaciones consistió en la motivación "divina" que recibió Bartolomé para predicar libremente las injusticias sufridas por los indios americanos a manos de los españoles; el segundo cambio radicó en la determinación de formarse intelectualmente; la tercera transformación radica en su capacidad para ejercer acciones políticas en favor del aborigen americano. Para terminar, se esbozan las conclusiones, en las que se destacan las contradicciones en las que se insertó la vida de este autor, aclarando que estas son parte normal del proceso de búsqueda del sentido de la vida de un hombre.

Palabras clave: sentido de vida, conversión, existencia, contradicción, experiencia.

* El presente artículo hace parte de la tesis para optar al título de Doctor en Filosofía en la Universidad Pontificia Bolivariana de la ciudad de Medellín. D0I: http://dx.doi.org/10.15332/ s0120-8462.2017.0117.04

* Filósofo, Universidad de Antioquia. Doctor en Filosofía, Universidad Pontificia Bolivariana. Docenteinvestigador, Universidad Católica Luis Amigó. Josepinomo@amigo.edu.co,wilmarjmo@gmail.com 


\title{
The meaning of life: the case of Bartolomé de las Casas
}

\author{
José Wilmar Pino Montoya
}

\section{Abstract}

This article makes a reflection of the meaning of life; the life of Bartolomé de las Casas. First, it focuses on the beginnings of his life. Subsequently, the moment called the "three conversions" is analyzed. The same ones that aroused multiple criticisms and contradictions. The first of these transformations consisted in the "divine" motivation that Bartolomé received to freely preach the injustices suffered by the American Indians at the hands of the Spaniards; the second change was in the determination to train intellectually; the third transformation lies in his capacity to exercise political actions in favor of the Native American. Finally, the conclusions are outlined, in which the contradictions in which this author's life was embedded are highlighted, making it clear that these are a normal part of the process for searching the meaning of a man's life.

Keywords: meaning of life, conversion, existence, contradiction, experience.

\section{0 sentido da vida: o caso do Bartolomeu de las Casas}

José Wilmar Pino Montoya

\section{Resumo}

Este artigo reflete sobre o sentido da vida; a vida do Bartolomeu de las Casas. Em primeiro lugar, foca-se na atenção nos começos da sua 
vida. Posteriormente, analisa-se o momento denominado as "três conversões". As mesmas que geraram múltiplas críticas e contradições. A primeira dessas transformações foi a motivação "divina" que recebeu Bartolomeu para predicar livremente as injustiças sofridas pelos índios americanos pelos espanhóis; a segunda mudança foi a determinação de se formar intelectualmente; a terceira transformação radica na sua capacidade para exercer ações políticas a favor do aborígine americano. Para concluir, esboçam-se as conclusões, nas que se destacam as contradições nas quais se inseriu a vida de este autor, aclarando que estas são parte normal do processo de busca do sentido da vida de um homem.

Palavras-chave: sentido da vida, conversão, existência, contradição, experiência.

\section{Introducción}

Para determinar el sentido de vida de un ser humano hay que tener presente que "todos los seres, desde luego, aspiran (a un fin) y con tal fin realizan cuantas acciones realizan naturalmente" (Aristóteles, II, 4, 415b2-4). Por otra parte, tal sentido es constituido, además, por los avatares y situaciones que suministra la realidad en la que se nace y las experiencias sensibles y particulares en las que se ve, por alguna razón inmiscuido el ser humano, que como cuestión normal pueden formar una personalidad profundamente contradictoria. Así es como el sentido de la vida "toma cuerpo y existencia en algo sensible, capaz, por lo tanto, de ubicarse más allá de los sujetos que la provocaron" (Coccia, 2011, p. 61).

La siguiente reflexión bibliográfica de Bartolomé de las Casas no pretende hacer una apología irreflexiva de su personalidad, sino aportar desde este trabajo, un punto de reflexión sobre el modo, a veces paradójico e incierto, en el que se puede erigir un pensamiento; una existencia; un sentido de vida. Tal y como lo afirma Dilthey (1995), "así se perfila de diversos modos la experiencia de la vida en los individuos. Su fondo común en todos lo constituyen las intuiciones del poder del azar, de la corruptibilidad de todo lo que poseemos, amamos o bien odiamos y tememos" (p. 42).

Desde otro punto de vista, la búsqueda del sentido de la vida resulta abismalmente contrapuesto y dudoso en principio a los ideales futuros, también está determinado 
por el pasado; por una serie de acontecimientos que han de ser tratados según el contexto; por el carácter particular del sujeto que va en búsqueda de su fin. Carácter que se puede manifestar en comportamientos: "mal sanos”, groseros, egoístas, obsesivos e ilusorios. Al respecto, dice Wahl (1956): "Heidegger enumera tres aspectos de la existencia, a saber: el proyecto enfocado hacia el porvenir, su determinación y su condicionamiento por su pasado y el carácter esencial del hombre” (p. 153). Estos comportamientos en ocasiones resultan perjudiciales para unos y altamente beneficiosos para otros, por ello y la construcción del sentido de vida de Las Casas no es la excepción entre todos los seres humanos de haber tenido un pasado; de haberse encontrado en un contexto particular en el que se formó, ni de haber manifestado ciertas actitudes y carácter que lo llevaron a ser un personaje como el ya descrito, pues tal y como lo afirma Cabada (1994), citando a Schopenhauer: "el hombre irrevocablemente está determinado, por su 'carácter' por los motivos concretos, que convierten las acciones del hombre en algo que ocurre con una 'determinación', que podría denominarse mecánica” (p. 63).

Esta exposición de la construcción del sentido de vida de Las Casas estará matizada por una serie de afirmaciones que no solo darán cuenta de las situaciones positivas de este personaje sino también de aquellas que lo llevaron a ser calificado de parcializado, interesado y poco objetivo en sus exposiciones y teorías. Lo anterior visualizará un proceso de vida lleno de contracciones y de momentos que trascurrían entre la obtención de sus intereses más egoístas y la defensa del bien común, como aquel que realizó de los indios americanos. Por ello afirma Borges (1990) que el protagonista (de esta historia) "será para unos un loco; para otros un santo; para la posteridad, un loco a lo divino [...] un malvado para los heridos y un héroe para sus patrocinados o para sus seguidores" (p. 14).

De este modo, la construcción de la personalidad de Bartolomé "ha quedado ante la historia como un signo en el que no faltan las aristas de la contradicción, con todo lo que tiene de estimulante y de admirable" (Galmez, 1989, p. 11). No obstante, la vida de un hombre como Bartolomé siempre tuvo un sentido: la ayuda a los más desfavorecidos.

Cabe concluir que Bartolomé de las Casas: “(al) igual que se dejó influir por las circunstancias, del mismo modo intervino luego en ellas. Llevando a término su misión, dio satisfacción tanto a su existencia interior como a lo que otros hombres exigían de él” (Kierkegaard, 1997, p. 39). 


\section{Los albores de la vida lascasiana}

Vale la pena comenzar, el análisis de la construcción del pensamiento lascasiano, diciendo que según la mayoría de los autores que se interesaron por estudiar por la vida y obra de este personaje, coinciden en que el nacimiento del sevillano sería en el año de 1474. No obstante, estudios realizados más recientes por Beuchot, (1994) citando a Rand y Weidmann (1976), llegaron a la conclusión de que su verdadera fecha de nacimiento fue en el año de $1484^{1}$.

Los acontecimientos y los sentimientos que lo unieron con América, según Olaizola (1991), comenzaron cuando a sus nueve años vio a Colón cargado con un sinnúmero de objetos y esclavos traídos desde el Nuevo Mundo; pero lo que más despertó el interés del futuro precursor de los indios hacia los nativos americanos fue el viaje que hizo don Pedro de las Casas ${ }^{2}$, su padre, a las Américas, en el mes de septiembre de 1493, cuando en la segunda expedición del almirante Colón se embarcó con este a las nuevas tierras. Abandonado cuando tenía nueve años, por su padre, Bartolomé se quedó en Sevilla con sus tres hermanas: Isabel, Catalina y Marina, y su madre, familia que no poseía otros medios de sustento más que una tahona y un horno para cocer pan.

Años más tarde, dice Beuchot (1994), y después de que su padre zarpara desde España hacia las Américas, murió su madre, quedando el hogar a cargo de su hermana mayor, Isabel de Sosa, quien se responsabilizó de administrar y cuidar el único sustento de la familia, la tahona, que no daba la suficiente ganancia para que la familia de Las Casas viviera de una manera cómoda y solvente. A partir de esta situación, Bartolomé comenzó a aceptar consejos de su hermana Isabel, para que se hiciera clérigo, ya que solo con recibir la orden menor obtendría lo suficiente para mantener a una familia que no tuviera muchas pretensiones.

En relación con su formación académica, se sabe que Las Casas se formó en leyes en la escuela de Sevilla, fundada por el famoso y prestigioso latinista de la época,

1 Esta última fecha de nacimiento, se tomará como punto de partida para el estudio del autor en cuestión, ya que antes de los estudios de H. Rand Parish y H. E. Weidmann, el año de 1474 se daba como fecha de nacimiento de Las Casas, pero después de estos estudios la crítica se inclina más por el año de 1484. Véase el artículo de estos autores (1976, pp. 385-403). ( Beuchot, 1994, p. 17).

2 En otros textos aparece el padre de Bartolomé de las Casas con el nombre de Francisco de las Casas. (Enzensberger, 1987, p. 37). 
Antonio Nebrija. Allí no solo recibió instrucción gramatical, sino también formación relacionada con el humanismo escolástico:

Por lo que se refiere a sus estudios, por razones de edad hay que desechar la opinión general de que acudiera a la Universidad y, con más razón aún, que poseyera ya el título de licenciado cuando en 1502 se embarcó para el Nuevo Mundo. Su bagaje intelectual no podía ser en ese momento más que los conocimientos adquiridos en las escuelas elementales de Sevilla. (Borges, 1990, p. 23)

A su construcción de vocación de colono, dice Losada (1970), contribuyó la admiración que le causó el triunfal regreso de Cristóbal Colón a Sevilla de su primer viaje a las Américas, pero, y sobre todo, el viaje de su padre y sus tíos a las nuevas tierras en la segunda expedición realizada por Colón. Ya que, con ellos, y decidido a probar suerte en estas tierras, se embarcó el 13 de febrero de 1502, cuando apenas tenía dieciocho años de edad. A esta edad, ya había recibido su primera tonsura ${ }^{3}$, título que le permitiría predicar en las Américas, labor que no pudo hacer, sino unos años más tarde, porque los primeros años de estadía en La Española y en Santo Domingo,

los dedicó, como todos los demás conquistadores, a la minería; a servir como soldado y a tomar parte en las sangrientas expediciones contra los indios rebeldes, emprendidas por el gobernador Fray Nicolás de Ovando y el capitán Diego Velázquez en la provincia de Xaragua. (Beuchot, 1994, p. 18)

Toda esta experiencia de participar en las cruentas y salvajes guerras contra los indios; su papel como colono; la explotación que él como conquistador ejercía contra los nativos, obligándolos a trabajar en las minas y a servirle como esclavos, fue lo que lo llevó a ser calificado, por algunos, de codicioso, ya que "en las muertes, sudores, hambres y vida desesperada que sufrían los indígenas mineros, alguna responsabilidad tuvo que caber en el propio Las Casas en su calidad de encomendero que se valía de sus encomendados para la extracción del oro" (Borges, 1992, p. 30).

3 Era en la iglesia bizantina el corte ritual del cabello de los niños al séptimo día después del bautismo. Se hacia en forma de cruz para significar el descenso de la bendición de Dios sobre la cabeza del niño. El corte de cabello significa además su primera ofrenda a Dios. En tiempos de Gregorio Magno en la corte papal existian cubicularrii tosurati, es decir, clérigos que recibian la tonsura a imitación de los monjes, para quienes la tonsura era el símbolo de su total consagración a Dios. Si los monjes y luego los clérigos practicaban la tonsura, los demás cristianos usaban el cabello moderadamente largo (Institutum Patristicum Augustinianum. 1998, p. 2136). 
En 1506, decide viajar a la ciudad de Sevilla, lugar donde pasó un año, dedicándose al estudio de las humanidades, para recibir las órdenes menores. Este título lo llevó a desempeñarse como doctrinero en las indias, lugar al que volvería, no sin antes ir a Italia. Estando en Italia, en 1507 Bartolomé de las Casas fue nombrado sacerdote, cuando tenía veintitrés años. Según Borges (1992), el interés que motivó su decisión “obedeció simplemente al afán de promoción política [...] en ella no influyó para nada el asunto de los indios, es decir, no se hizo sacerdote para atenderlos espiritualmente" (p. 42).

Una vez ordenado sacerdote, Las Casas decide volver a España y posteriormente al Nuevo Mundo y reanuda la explotación de su hacienda y la recogida de oro, suspendida años atrás por su viaje a Sevilla. Se radica en Santo Domingo, donde permaneció alrededor de unos tres años cumpliendo labores como clérigo, dedicado a la granjería y a las funciones propias de su ministerio, sobresaliendo especialmente en la predicación. Allí, fue el primer sacerdote en cantar una misa en América. No obstante, el futuro defensor de los indios no se comportó de manera diferente a los demás conquistadores, porque en 1511 parte hacia Cuba a realizar una expedición, en compañía de Diego Velázquez, Hernán Cortés y Pánfilo Narváez. Tal expedición se desarrolló dentro de un ambiente pacífico y sin mucho derramamiento de sangre, en tanto que los indios se entregaron pacíficamente, lo que facilitó el sometimiento completo de los habitantes de la isla y su distribución sin resistencia de las tierras conquistadas entre los que hicieron parte de la contienda; entre ellos, y como bien se sabe, estaba Las Casas, quien al momento de la repartición no se quedó corto a la hora de repartidas las pertenencias:

Él recibió allá una buena ración, buen número de indios le fueron “encomendados". También le tocaron las tierras correspondientes, con eso Las Casas desarrolló un interés personal en aquel sistema de explotación: tenía minas y haciendas rentables y se encargaba, como dice él mismo, más bien de su posesión y de sus minas, en lugar de la doctrina cristiana porque estaba tan ciego como los pobladores mundanos ${ }^{4}$. (Enzensberger, 1987, p. 38)

En palabras de Borges (1992), Bartolomé, al igual que aquellos a quienes más tarde condenaría, se aprovechaba de los indios ocupándolos en las cementeras, en las granjerías y en las minas, sacando oro, todo bajo precarias situaciones de hambre, pues no

4 Esto lo confirma el mismo Bartolomé en su historia de las indias donde admite algunos comportamientos suscitados por el interés en la posesión de minas y riquezas. 
alimentaba suficientemente a los indios, ni hacía caso de los lamentos que por falta de salud ellos proferían, ni mucho menos se preocupaba de su vida religiosa. Esto demuestra que durante este período fue poco compasivo y piadoso con los indios.

En la utilización de estos indios se comportaba de la misma manera que lo hacían [...] los restantes encomenderos de Cuba y lo habían hecho anteriormente los de La Española: haciéndoles trabajar lo más posible, hasta el punto de que Velásquez le recuerde más tarde que "comenzaba a tener fama de codicioso" y que estaba en las cosas del mundo como los otros azolvado [...] y despreocupado de la formación religiosa de sus empleados. (Borges, 1992, p. 50)

Por esta misma época, comenzaron a pasar a Cuba algunos de los padres dominicos como fray Pedro de Córdoba, quien fue de los que alcanzó más fama y tuvo mayor influencia en la vida de Las Casas porque "en su predicación se mostraba colérico, pero como si su cólera estuviera atizada por un juego divino" (Olaizola, 1991, p. 73) y porque sus sermones tenían tal efecto que conmovían a los feligreses, generando en ellos comportamientos más humanos hacia los indios.

Pero esto no fue lo que realmente hizo de Bartolomé un defensor de los indios. Lo que más encendió su fuego e iluminó su corazón para que fuera un incansable e incondicionado luchador por los aborígenes americanos fue un sermón muy famoso que pronunció fray Montesinos en la ciudad de Santo Domingo. En este sermón, presenciado por todos los vecinos y las altas autoridades, fray Montesinos increpaba a los españoles diciéndoles las siguientes palabras:

Todos estáis en pecado mortal y en él vivís y morís por la crueldad y tiranía que usáis en estas inocentes gentes, decid ¿Con qué derecho y con qué justicia, tenéis en tan cruel y horrible servidumbre a aquellos indios? [...] ¿no son hombres? [...] ¿̇o tienen ánimas racionales? [...] etc. (Freide, 1978, p. 21)

Los sermones y los actos de Montesinos que buscaban que los encomenderos trataran bien a los indios llegaron hasta oídos de Las Casas, encontrando así aliados para su fin, porque él también estaba de acuerdo con esas denuncias, las mismas que comenzó a predicar en cada una de las misas. Esto llevó a Bartolomé a sentir un gran aprecio por los dominicos, en especial por los personajes de fray Pedro de Córdoba y fray Antón Montesinos, hasta tal punto que cuando estos llegaron a Cuba, salió a su encuentro 
con un buen aparejo de mulos. A este momento de la vida de Las Casas también se le conoce como su primera conversión.

\section{Primera conversión}

La primera transformación del defensor de los indios tiene su punto relevante cuando Bartolomé decide confesarse con fray Montesinos, sacerdote dominico que le niega la absolución por tener indios en encomienda y por negarse a dejarlos, argumentando estar cumpliendo fielmente las leyes proferidas por el Rey. Consternado entonces, y sumido en un profundo desasosiego y tristeza y después de leer el Eclesiástico, capítulo $34^{5}$, para preparar un sermón que debía dar en la recién fundada provincia del Espíritu Santo, Bartolomé “recibe el llamado de Dios”, acontecimiento que relató así: "Pero aquel atardecer, sería un poco antes de la caída del sol, sentí una llamada en mi corazón y me pareció que era el mismo Señor quien me estaba cantando los versículos del salmo" (Olaizola, 1991, p. 10).

Así, pues, y camino a la Provincia del Espíritu Santo, Las Casas encuentra lo que muchos historiadores y estudiosos han denominado como su primera conversión, hallando de esta manera claridad para su espíritu y desasosiego para las intranquilidades de su alma, quedando cada vez más motivado y con mayor libertad para predicar a los cuatro vientos la injusticia, el abuso y las violaciones que estaban cometiendo los españoles con los indios. Esta conversión acabó también con su interés por mantener indios a su cargo, pues su predicación no tendría sentido si todavía seguía siendo un encomendero. Renunció, entonces, a las haciendas y con ellas dejó, además, a los indios que le habían sido encomendados y a mediados de 1514 disuelve la sociedad con Rentello, quien era desde hacía muchos años su amigo, socio y consejero, para convertirse por fin en el más dedicado y aguerrido defensor de los nativos, lo que quizá sería difícil de creer, más cuando ya era un hombre maduro de más de treinta años, integrado solamente al orden social y que de un momento a otro cambia radicalmente su modo de pensar y de actuar, solo por haber leído un pequeño fragmento de la Biblia.

5 El capitulo del eclesiástico el cual aparece en las Sagradas Escrituras dice asi: "Pan escaso es la vida de los indigentes, y quien se lo quita es un hombre sanguinario. Mata al prójimo quien le priva de su subsistencia y derrama sangre el que retiene el salario del jornalero" (Enzensberger, 1987, p. 38). 
Como se observa, esta conversión dejó un manto de duda en quienes se han interesado por la vida del fraile. A ella la califican de anormal y chocante, ven en este hecho un acto provisto de vanagloria, inmoral e impropio de alguien consagrado a la vida sacerdotal. Le falta, dicen, la fuerza moral de otros a quienes se ha considerado santos. Por esta razón, dice Menéndez (1963):

Debemos considerar esta conversión, ese radical cambio de ideas y de conducta como efecto de alguna emoción personal ajena al tema indiano... la cual fue poderosa para provocar el afloramiento de la enfermedad. Realiza entonces un noble acto de gran gratitud, mezclado con un solemne rasgo de vanidad egocéntrica con jactancia de santidad. (p. 14)

Sobre este mismo acto se pronuncia Borges (1990) al decir que:

En realidad [...] no se trata de una conversión plena, en el sentido de que Las Casas se transforma de incrédulo en creyente [...] se trata solo, pero nada menos, que la transformación de un sacerdote encomendero en un sacerdote anti-encomendero ante la estremecedora toma de conciencia de que los encomenderos, y él con mayor razón por ser además sacerdote se encontraba en estado de "damnación", es decir, en pecado mortal permanente y en vía de condenarse debido a la posesión de las encomiendas. (p. 60)

En fin, y a pesar de todas estas contradicciones en su decisión, ya todo está dado para que el defensor de los indios se diera a la tarea de su lucha; es así como, y después de haber liquidado todos sus negocios y haciendo escala en Santo Domingo donde se conectaría con fray Pedro de Córdoba, otro luchador contra los excesos de encomenderos, Las Casas "viaja a España y junto con él también parte el ya nombrado fray Antón de Montesinos. Llegan a Sevilla en octubre de 1515, convencidos de que dadas las circunstancias y el autogobierno de los 'americanos', solo una enérgica intervención podría cambiar la situación” (Freide, 1978, p. 26).

Al llegar a España, lo primero que hace ahora el futuro defensor de los indios es presentarse ante el rey Fernando, el Católico, para decirle y hacerle ver que en las tierras conquistadas no se cumplían sus leyes y que, por el contrario, se cometían toda clase de abusos y atropellos. Este lo escucha atentamente, entendiendo que sus palabras importaban mucho a sus intereses, pues con sus relatos e historias podría 
muy bien saber qué pasaba en "América", con respecto a los abusos y calamidades que sufrían los indios. Los relatos de Las Casas conmovieron al Rey acordando un nuevo encuentro en la ciudad de Sevilla a donde viajaría el monarca al finalizar la Navidad. Acordada la nueva cita y aconsejado por fray Montesinos, pacta un encuentro con don Juan Rodríguez de Fonseca, ministro universal de los indios; este lo recibió con mucha displicencia y poca atención, tal vez, porque pensó que Bartolomé exageraba con respecto a los acontecimientos vistos en La Española. Fonseca lo expulsa y "comenzamos con esto a pensar que no es prudente prescindir de la opinión de algunos antiguos contemporáneos cuando califican a Las Casas como hombre de 'invenciones e imaginaciones' y como 'injuriador' [...] pues el autor de la destrucción inventa cifras y maldades" (Menéndez, 1963, p. 17).

Llegó así la fecha y a finales de la Navidad Las Casas parte para Sevilla, donde se entrevistará por segunda vez con el Rey. De igual modo, el Rey parte hasta allí en su espera para cumplir lo prometido con Bartolomé. Pero los designios de la azarosa vida no favorecieron los intereses de Las Casas, porque antes del día previsto para la reunión el Rey muere el 23 de enero de 1516, camino a Guadalupe, donde pediría consejo a nuestra Señora.

Muerto el Rey, y mientras tomaba posesión el nuevo monarca, "Carlos V"6, se encargaron de la gobernación del Reino de Castilla el cardenal Cisneros, perteneciente a la orden franciscana, y el cardenal Adriano de Utrecht, a quien llamaban el Emperador, por serlo, de Carlos. Aprovechando la posesión y demostrando gran inteligencia, Las Casas decide visitar a los nuevos, pero transitorios gobernadores, con el fin de felicitarlos por tan notable distinción. Es así y después de presentar su relación de agravios ante el cardenal Adriano, este le muestra su confianza y lo convierte en su veedor, en un hombre que lo valora y le presta mucha atención, comenzando juntos una cruzada para ayudar a los indios.

En junio de 1516, se realiza una junta para discutir y reformar las Leyes de Burgos promulgadas en 1512. Allí, el emperador Adriano propone una reforma, liderada por Las Casas, la cual consistía en la abolición del régimen de los repartimientos. Además, en esta ocasión le fue encomendada a Las Casas la tarea para que él mismo se encargara de ordenar, por escrito, cómo habrían de ser gobernados los indios,

6 Por aquella época, Carlos $V$ tan solo era un joven de quince años de edad, además, este no residía en España (Enzensberger, 1987, p. 42). 
tarea que la desarrolló con la ayuda de fray Antonio Montesinos. Ahora contaba Bartolomé de las Casas con todas las herramientas "legales" para intentar recuperar la libertad de los indios, suprimiendo las encomiendas.

Todas estas ideas, revolucionarias para la época, llevaron a que al sevillano se le concibiera por muchos como loco. "Sus contemporáneos lo consideraban loco, sin embargo, en aquella mezcla de audacia e ingenuidad suya estribaba tal vez su mayor fuerza: siempre, renovada, acababa por proteger a Las Casas y sorprender a sus adversarios" (Enzensberger, 1987, p. 41). Esta audacia fue lo que quizá conquistó la confianza de la reina y el rey de Castilla, pues no dudaron en nombrarlo en 1516 protector universal de todos los indios de las Américas, título que se merecía por considerársele muy conocedor y amoroso de los indios.

Nombrado ahora protector de los indios, viaja a La Española para poner en práctica las reformas que se había propuesto en las Indias para proteger a los nativos. Para poner en práctica el plan que liberaría a los indios de su situación, se designa a un grupo de frailes jerónimos, con quienes al parecer nunca se entendió y a quienes siempre desdeñó, acusándolos de pocas letras, ignorantes y culpables de traicionar su misión y llevarlo al fracaso de sus remedios para con los indios.

En 1517 Bartolomé de las Casas vuelve a España, después de darse cuenta de que se había equivocado al elegir el grupo de frailes Jerónimos ${ }^{7}$ escogidos para poner en marcha su proyecto de liberación de los nativos, porque ellos, según el mismo Las Casas, fueron incapaces de realizar el trabajo encomendado.

Al llegar a España, el 3 de junio de ese mismo año, "se planta ante Cisneros, quien regía mientras venía el rey Carlos $\mathrm{V}$ y le pide la abolición efectiva de la esclavitud, la prohibición de los atropellos y la implantación de un orden justa" (Beuchot, 1994, p. 19); pero para sorpresa y desilusión de Las Casas, por esta época el cardenal Cisneros ya había muerto, y él, destituido del cargo de protector de los indios, se sume en gran tristeza y desánimo y decide volver con su familia; para ello, quiso pedirle consentimiento a fray Diego de Deza, quien se desempeñaba como obispo de Sevilla. A él quería solicitarle que le encaminara en su diócesis sacerdotal regular, lo que nunca sucedió porque fray

7 Sobre este argumento de los Jerónimos, dice Enzensberger que "probablemente (Bartolomé) ignoraba que los miembros de la comisión - dos obispos o un funcionario- tenian intereses. Un interés material, que consistía en que la explotación de las indias continuara produciendo sus réditos y de las que recibian importantes ingresos" (Enzensberger, 1987, p. 41). 
Diego con sus consejos y argumentaciones lo hizo renunciar a su cometido, convenciéndolo de nuevo a seguir por el camino de defender las almas; es decir, los indios que sufrían en el Nuevo Mundo. “Ahora Las Casas perfilaría y afirmaría doctrinalmente sus primeros estudios, insistiendo acaso en la soberanía de los señores naturales indios, esto es, apartándose cada vez más de la realidad práctica” (Menéndez, 1963, p. 28). Lo importante, y a pesar de su poca instrucción teórica, es que para la época Las Casas ya

no era un novato, sino un político experimentado y conocedor íntimo de la manera de pensar de los gobernantes. Las Casas no había perdido su inocencia, estaba menos dispuesto que nunca a transar con sus opositores, pero además se había desarrollado con sorpresiva rapidez hasta el punto de convertirse en un táctico de grandes vuelos ${ }^{8}$.

Constituyó entonces un nuevo proyecto que pretendía servir como remedio a la enfermedad que padecían los indios: la injusticia, los abusos y maltratos.

La propuesta consistía en "llevar buenos labradores, que conquistasen la tierra con su trabajo y las almas de los indios con su ejemplo de buenos cristianos" (Olaizola, 1991, p. 126). Esta propuesta fue denominada "remedio para la tierra firme". Remedio que demoró por escribirse unos dos años, de manera que el 12 de octubre de 1518 se aprobó la propuesta y se comenzó inmediatamente a recoger los labriegos para mandar a las nuevas tierras y especialmente a Santo Domingo, para donde se embarcaron doscientos labriegos de quienes pronto se recibieron noticias, por parte de los padres dominicos. Ellos dieron noticia de que "de los doscientos labriegos algunos habrían muerto, otros andaban por los hospitales, los demás se habían dado a robar en compañía de los de siempre" (Olaizola, 1991, p. 126).

Como apenas sería lógico, este nuevo plan lascasiano, para rescatar y liberar a los indios de los españoles, no tuvo resultado alguno y su fracaso llevó a Las Casas a renunciar al proyecto de labradores y a plantearse nuevas alternativas para colonizar y evangelizar pacíficamente a los habitantes de la tierra firme, para ello, consiguió la firma de la capitulación por parte del rey y el nombramiento como administrador de

8 Enzensberger agrega que "a través de algunos pasajes de la brevisima relación de las Indias, pueden reconstruirse sus argumentos, siempre partió de la suposición que el rey no sabía nada de los crímenes que se cometían en su nombre; con engaños y persuasiones dañosas que se hicieron al rey nuestro señor, como siempre se ha tratado de encubrir la verdad de los daños y perdiciones que Dios y las ánimas, y su estado, recibian en aquellas indias" (Enzensberger, 1987, p. 43). 
todos los territorios que comprendían las Costas de las Perlas. Allí se desenvolvería con mayor autonomía y libertad para proteger sus dominios.

Se embarca de nuevo para La Española el 11 de noviembre de 1520, llega a la Costa de las Perlas e inicia con sus habitantes experimentos sociales de colonización. Pero de nuevo el intento fracasó, porque, interesados por las riquezas y los bienes que tenían las nuevas tierras, los labriegos se dedicaron a saquear y a asaltar a aquellos predios y a apoderarse de todo lo que se encontrara allí. Consternado por estos acontecimientos, Bartolomé decide dejar la Costa de las Perlas y viajar a tierra firme; se instala, entonces, en Cumaná (agosto de 1521), región de Venezuela, en un convento de la comunidad de los franciscanos, y quiso en este lugar iniciar por tercera vez un proyecto de colonización pacífica, que por cierto según algunos biógrafos, y contrario a sus propósitos, Las Casas con esta propuesta no estaba interesado en ayudar a los indios, su motivo, dicen, era económico; las perlas que se encontraban en el territorio de Cumaná eran su principal interés y los motivos que lo llevaron a practicar tal proyecto.

Sin embargo, no fue posible llevar a cabo este nuevo proyecto, porque los españoles que habitaban en estas tierras se encontraban en una difícil situación económica: acosados por el hambre y en malas condiciones de salud, no se sentían motivados a tomar parte en la propuesta. Bartolomé sale del lugar y quince días más tarde los campesinos españoles que allí se encontraban y los franciscanos que los acompañaban fueron asesinados y masacrados por algunos indios que atacaron el lugar, sembrando la mortandad y el terror.

Sin duda alguna, todas estas expediciones eran de calificarse como admirables por la intensión de ayudar a los indios, pero no se puede desconocer que todos estos fracasos nacieron del desconocimiento, del egoísmo y de los deseos de sobresalir del fraile, además de la gran carga de fantasía, ilusionismo y falta de realismo por parte de Bartolomé. Comportamiento del cual hacen mención ciertos autores como Borges, quien dice al referirse a los actos de Las Casas que "la falta de realismo se refleja en que basó todos sus pensamientos en lo que debía, no en lo que se podía hacer" (Borges, 1990, p. 267). En este mismo sentido se pronuncia Menéndez al decir que “el proyecto para la colonización de Cumaná [...] contenía disposiciones fantásticas, o extravagantes” (Menéndez, 1963, pp. 43-44). 
Con este nuevo fracaso, el padre Las Casas se sume en una profunda depresión y para "consolarse se dedicó a conversar con sus amigos los dominicos que se encontraban en La Española y en especial conversaba con Fray Domingo Betanzos, quien le aconseja que se hiciese fraile dominico" (Losada, 1970, p. 195). Es a este acontecimiento, el de convertirse en fraile dominico, al que la mayoría de los autores han denominado en la vida de Las Casas su segunda conversión.

\section{Segunda conversión}

A la invitación que le hace el padre Betanzos, Bartolomé de las Casas responde de manera positiva y toma su hábito como padre dominico, en el mes septiembre de 1522, en la ciudad de Santo Domingo, y ocurre lo que muchos historiadores han denominado la "segunda conversión".

Hizo su noviciado y profesó en 1523. A pesar de que ya era sacerdote y contaba con 37 años de edad, en la Orden le exigieron tres años más de estudio. Fray Bartolomé aprovechó ese tiempo para acabar de pertrecharse de sólida doctrina teológica y jurídica [Santo Tomás, Cayetano ${ }^{9}$, Victoria, etc.] Que usaría a favor de los indios. Por esta época redactó el De único vocationis modo, donde expone claramente que la conversión al evangelio debe lograrse por la persuasión pacífica y no por la violencia. (Beuchot, 1994, p. 20)

Terminado su largo y exhaustivo período de estudio, en 1526 toma posesión como prior en un convento en Puerto Plata, en la costa norte de La Española, lugar que le sirvió para predicar, ahora desde su nueva orden, a indios y cristianos. También sentó los fundamentos teóricos de sus acciones futuras concibiendo e iniciando sus primeros escritos sobre la Historia de las Indias, la Apologética Historia Sumaria, entre otras obras.

9 "Cayetano (Tomás de Vio) fue un religioso dominico (1468-1534). Nació en Gaeta, murió en Roma. Ingresó en la orden dominicana a los 16 años de edad, estudió en Padua, interpretó el Libro de los Proverbios y fue maestro de estudios, profesor de teología en Brescia y Pavía y, por último, catedrático de Metafísica en la universidad. En esta época compuso su comentario al tratado De ente et essentia de santo Tomás, en el que se ocupa en los problemas suscitados por el averroismo, y en las objeciones del escotismo. Dos años más tarde, abandonó su cátedra y pasó en el año 1500 al convento de Santa María de las Gracias de Milán. En el mismo año fue nombrado procurador general y profesor de Teología y Filosofia en la Universidad de París y Roma" (Enciclopedia de la Religión Católica, 1952, pp. 596-597). 
En conclusión, sus experiencias y conocimientos eran bastante avanzados, lo que se observó en sus adelantos en antropología, en la opinión de que las culturas americanas no podían ser entendidas bajo los mismos parámetros de las europeas; en su comparación de los templos de los mayas con las pirámides de Egipto; en la indicación de la no superioridad de los españoles; y en la concepción de la cultura humana como un proceso evolutivo. No obstante,

\begin{abstract}
Las Casas podía sentirse inferior a los dominicos de formación juvenil y completa; sus enemigos, veremos, que lo menospreciaban por no haber estudiado sino unos pocos cánones, es decir por no ser docto en teología, y por no haber estudiado en Salamanca, dos escatimas que eran causa de inferioridad notoria en las disputas que el agitaba. (Menéndez, 1963, pp. 67-68)
\end{abstract}

Pero y a pesar de esta situación, Las Casas no se aminoró y ahora, con mayores argumentos teóricos, reinicia en 1531 su labor como defensor de las Indias.

En su nuevo papel como fraile dominico y bajo las características de su orden y con mayor conciencia y fundamentación intelectual de los problemas indígenas, reemprende su lucha política en pro de los indios de América, iniciando sus viajes a lo que es hoy Venezuela, Perú, Nueva Granada, El Darién, Guatemala y Nicaragua, donde en 1534 combate el tráfico inhumano de esclavos indios. Pasa luego por el Salvador, Guatemala y México. Travesía donde logró, según el mismo Las Casas, la pacificación de Tezulutlán, tierra considerada de guerra.

Durante esta etapa y por defender los derechos que no se le reconocían a los aborígenes, sufre diversas persecuciones y encarcelamientos, pero su persistencia y espíritu de lucha no deja que estos hechos lo debiliten y lo dejen apartar de la defensa que había comenzado por los aborígenes, pues nada ni nadie parecía detener su ilusión y su misión humanitaria, porque hacia 1539 ocasionó en Nicaragua un escándalo que sirvió para que sus enemigos lo acusaran de traición contra la corona, todo porque el fraile dominico, con uno de sus sermones, ocasionó la deserción de los soldados que habían viajado a La Española a hueste expedicionaria, lo que terminó con la derrota de la debilitada tropa. Fundamentado en este acontecimiento, el capitán, en Madrid, acusa a Las Casas de traición, lo que lo obliga a viajar a España para preparar y argumentar su defensa, acusación que concluyó con la negación de las autoridades judiciales de entablar algún procedimiento legal contra el fraile. 
Permaneció en la metrópoli por cuatro años más, tiempo que empleó para escribir su Brevísima relación de destrucción de las Indias, para consagrarse como obispo y reunir a los mejores teólogos de España y escribir con ellos un código legal que trató sobre la cuestión de los indios, código que se denominó Las leyes nuevas de Indias ${ }^{10}$, las mismas que firmó el emperador Carlos V el 20 de noviembre de 1542 y con las que se mejoró notablemente la condición, el trato y la vida de los indios en las Américas, hasta tal punto que evitó la extinción total de los indígenas.

Tres años más tarde, la ilusión de seguir protegiendo a los indios fracasó definitivamente dado que el 20 de noviembre de 1545, bajo la opresión de los grupos americanos de poder, Carlos V abrogó aquellas leyes porque su puesta en práctica en las Indias ocasionaba una resistencia organizada donde la mayor parte de los jueces se solidarizaron con los ricos, quienes justificaron que sus vidas y su estadía en las Indias dependían por entero de la esclavitud.

De 1544 a 1550, Bartolomé se desempeñó como obispo de Chiapas en México. Carlos $\mathrm{V}$, quien le tenía gran estimación, quiso nombrarlo en Barcelona obispo del Cuzco, pero el fraile no aceptó su propuesta; sin embargo, luego en una jugada política el rey lo nombró como obispo de Chiapas, donde escribió y publicó una obra que llevaba por título Aquí se contienen unos avisos y reglas para los defensores que oyen confesiones de los españoles que son o han sido encargo a los indios de las Indias del mar Océano (Enzensberger, 1987, p. 48). En este manual o confesionario de Las Casas consignó

10 "Las leyes de Indias constituyen una recopilación de las distintas normas legales vigentes en los reinos de Indias, realizada durante el reinado de Carlos II. Básicamente estas eran las Leyes de Burgos, las Leyes Nuevas y las Ordenanzas de Alfaro. Fueron promulgadas mediante real cédula el 18 de mayo de 1680, y su texto resume los principios políticos, religiosos, sociales y económicos que inspiraron la acción de gobierno de la monarquía española. Las disposiciones jurídicas están ordenadas en 9 libros, que contienen alrededor de 6.400 leyes. Ley 1: Refiere a los asuntos religiosos, tales como el regio patronato, la organización de la Iglesia, la cultura y la enseñanza. Ley 2: Trata la estructura del gobierno indiano con especial referencia a las funciones y competencias del Consejo de Indias y las audiencias. Ley 3: Resume los deberes, competencias, atribuciones y funciones de virreyes, gobernadores y militares. Ley 4: Concierne al descubrimiento y la conquista territorial. Fija las normas de población, reparto de tierras, obras públicas y minería. Ley 5: Legisla sobre diversos aspectos del derecho público, jurisdicción, funciones, competencia y atribuciones de los alcaldes, corregidores y demás funcionarios menores. Ley 6: Trata la situación de los indígenas, su condición social, el régimen de encomiendas, tributos, etc. Ley 7: Resume los aspectos vinculados con la acción policial y de la moralidad pública. Ley 8: Legisla sobre la organización rentística y financiera. Ley 9: Refiere a la organización comercial indiana y a los medios de regularla, con especial referencia a la Casa de Contratación" (Sarmiento, 1988, pp. 25-56). 
la manera como se había de proceder para adjudicar los bienes de un moribundo y cómo se debía hacer para otorgar los bienes redictos.

En relación con el obispado en Chiapas, se dice que:

Las Casas es el prototipo del sacerdote que quizás no lo debía haber sido, al menos en la América de entonces... Un hombre como él, eminentemente teórico, arbitrista, apasionado y extremista, era el menos indicado para realizar una labor pastoral de obispo que exigía moderación, tacto, comprensión y hasta cierta ductilidad (Borges, 1990, p. 276)

Fue quizá por esta razón que su función en la diócesis no fue la mejor, en tanto quedó en descrédito "por el ningún cuidado que el Obispo dedicó a los indios y el mal recaudo que dejó para los españoles” (Menéndez, 1963, p. 218).

\section{Tercera conversión}

Las Casas, hecho un anciano, se retiró a un lugar solitario donde la presión de las haciendas no podría ya atacarlo y en 1550 renuncia a su obispado en Chiapas. Fue por este tiempo que sucedió su tercera conversión. En 1551 se dedica a estudiar y trabajar como simple fraile en el Colegio de San Gregorio, donde pidió vivir hasta su muerte; allí compuso numerosas obras, unas de denuncia y otras de profunda y sólida lucidez en temas de humanismo, que lo hacían tener una visión original de los acontecimientos de su tiempo.

En 1552 viaja a Sevilla con el fin de reclutar frailes para enviar a América, y aprovechando su estadía en aquel lugar visita la Biblioteca de Colombina, sitio donde se encuentra el documento que le ayuda a terminar una de sus grandes obras y que aún no se había culminado: Historia de las Indias. Regresa de nuevo al Colegio de San Gregorio y escribe su obra La apologética historia sumaria, obra que se desligó de Historia de las Indias.

En 1555 y encontrándose Felipe II con problemas económicos, los encomenderos del Perú le proponen al rey la concesión o perpetuidad de las encomiendas a cambio de una gran suma de dinero (nueve millones de ducados). El rey aceptó anegado por sus problemas económicos. Fray Bartolomé se da cuenta de tal decisión y se enfrenta 
al rey haciéndole saber de la injusticia que cometería si accede a lo que le proponen los encomenderos. Le envía, entonces, un memorial y numerosas cartas donde en términos muy fuertes le advertía que si mantenía su decisión se convertiría en cómplice de la injusticia y de la desgracia que padecieran los indios. El rey, preocupado como consecuencia de lo dicho por Las Casas en las cartas y como un triunfo contra la injusticia que se cometería por los españoles en el Nuevo Mundo, accedió a sus reclamos y suspendió la famosa perpetuidad de las encomiendas.

La vida tan activa de fray Bartolomé de las Casas no le impidió que escribiera más de cuatrocientos escritos relacionados con los problemas de los indios en "América". Entre estos escritos sobresalen: Historia de las Indias; su Brevísima relación de la destrucción de las Indias; Los tesoros del Perú y el Tratado de las doce dudas, entre otras. En 1564, sintiendo su final, redacta su testamento donde escribe una notable carta para el recién elegido papa Pío $\mathrm{V}$, papa dominico que años más tarde fue consagrado como hombre santo. En este testamento y como último esfuerzo para ayudar a los indígenas, intercede por estos, argumentando que ellos son la nueva Iglesia. En este mismo año y en el Consejo de Indias ${ }^{11}$ estando presente fray Alonso de la Veracruz, gran amigo de Las Casas, se da lectura a un memorial donde relata sus luchas, considerándose este como supremo manifiesto de su vida evangélica.

En una actitud crítica en defensa de los indios “americanos”, muere fray Bartolomé de las Casas en el convento (estudio general que la Orden de Santo Domingo tenía en el santuario de Nuestra Señora de Atocha) de Madrid, el 18 de julio de 1566, cuando ya tenía unos 82 años de edad. "Se termina así la vida de alguien que, por sus luchas en pro de la justicia, merece perfectamente y mucho más que otros, el nombre de 'Profeta' y 'Libertador' de los oprimidos” (Beuchot, 1994, p. 27).

11 "Con relación al poder de este Consejo, dice la Ley II: porque los de nuestro Consejo de Indias, con más poder y autoridad nos sirvan y ayuden a cumplir con la obligación que tenemos al bien de tan grandes Reinos y Señorios: es nuestra merced y voluntad, que el dicho Consejo tenga la jurisdicción suprema de todas nuestras Indias Occidentales, descubiertas y que se descubrieren, y de los negocios, que de ella resulten y dependan, y para la buena gobernación y administración de justicia pueda ordenar y hacer con consulta nuestra las Leyes, Pragmáticas, Ordenanzas y provisiones generales y particulares, que por tiempo para el bien de aquellas provincias convinieren". (Sarmiento, 1988, pp. 101-102). 


\section{A modo de conclusión}

En resumen, la personalidad de Las Casas para muchos fue contradictoria y aporética, por ello, y para varios autores, no puede ser catalogado como un hombre brillante, cuerdo y reflexivo en todos sus actos, era un hombre aturdido e irreflexivo, falto de juicio y paranoico; "su lucidez habitual hace que su anormalidad sea caso difícil de establecer y graduar, como es muy difícil, respecto a algunos enfermos mentales, el decidir si reducirlos, o no, a un sanatorio” (Menéndez, 1963, p. 316).

Su delirio de grandeza también era una particular característica del sevillano, esto se notaba en sus repetidas autoalabanzas. Él dice ser el único protagonista de muchas situaciones que se dieron a favor de los indios y de España: se hizo temer de los jerónimos, impidió la pérdida de Yucatán, sometió a la isla de Cuba, pacificó a Enriquillo, es el escritor de las Leyes de indias, entre otras obras.

La paranoia megalómana del fraile se manifiesta, también, en el ensalzamiento de su gran virtud y grandes fortunas, pues dice que Dios lo dotó de grandes virtudes que a ningún otro hombre ha dado.

Las Casas, según lo expresado por Menéndez (1963), es un personaje irracional y contradictorio, vanidoso y de actos chocantes, difamador y altamente exagerado en sus apreciaciones. Por ello, este autor dice:

Lo defectuoso patológico que caracteriza a Las Casas debe ser observado especialmente en su manifestación exageratoria. Todos cuanto tratan del famoso fraile se ven obligados a hablar de las exageraciones lascasianas, pero no las consideran en modo debido, según repetidas veces hemos reparado. Ahora debemos fijarnos más particularmente en la exageración de la maldad humana, que es donde más visible es el hecho de que para la exageración lascasiana no hay nombre adecuado en el léxico español; hemos tenido que llamarla enormización. (p. 321)

El ejemplo más sobresaliente de este comportamiento es lo relatado en su Brevísima historia de la destrucción de las Indias, donde y para llevar sus acusaciones ante el rey sobre las prácticas de los españoles hacia los indios, inventa y exagera sus descripciones. 
Otra de las críticas que se le hacen al defensor de los indios es la de no gustarle trabajar con aquellos que defendía, no trabajó en su instrucción, tampoco en mejorarles su condición de vida, dichas acciones las dejaba a cargo de sus compañeros. Era, según dicen, un estorbo en la aplicación eficiente, rigurosa y benéfica para los indios; su lucha estaba motivada más por el odio hacia los españoles que por el amor que según el mismo decía sentir por los nativos. En sus pasajes no relata actos de caridad, amor o cordialidad hacia sus defendidos, nunca se muestra abrazándolos o ejercitando actos de caridad con ellos.

Bartolomé predicaba que quien viviera con los dineros traídos de las Indias no podía alegar buena fe; no obstante, él se benefició en contadas ocasiones con las riquezas indianas. Su primer encargo estaba financiado por los indios, el mismo origen tenía el sueldo que le pagaron cuando fue nombrado como procurador de estos.

Las Casas juzgaba toda conquista como tiránica, usurpatoria y nula, todo lo de las indias había que plantearlo de nuevo, y sin embargo él entra a ser obispo con 500.000 maravedís de sueldo en la organización de aquella diabólica conquista, etc. Todos estos contrasentidos indican que ese ultrarrigorismo estaba en pugna con la realidad como parte de una menta anómala que los psicólogos habrán de estudiar. (Menéndez, 1963, p. 337)

El defensor de los indios también padecía, según Borges (1990), una dolencia parecida a la de Don Quijote. Era ufano, orgulloso, lleno de sí, ingenuo, arbitrista, choca contra la realidad, fracasa "rompiendo lanzas". En fin, parecidos en unos casos y diferentes en otros. Dos personajes, según algunos, semejantes, pues coexiste en ellos dos personalidades que al ser descritas hay que fundirlas en una sola.

En el terreno de lo profano, sus nobles ideales y su visión daltónica de la realidad indiana lo asemejan al idealista y también daltónico Don Quijote de la Mancha, quien, en sus esfuerzos por "desfacer entuertos", no vio por sus polvorientos caminos más que a desvalidos que había que proteger y a malandrines que había que descabezar. (Borges, 1990, p. 306)

En relación con "sus estudios jurídicos, históricos y teológicos no tuvieron muchos lectores después de ser publicados debido a su excesiva extensión, a su minuciosa argumentación y en ocasiones, dificultoso estilo" (Hanke, 1965, p. 42). 
Por ello y retomando nuevamente las palabras de Hanke (1965), se puede decir que "la imagen $[. .$.$] de Las Casas es la de un fraile disputador que no observaba$ el mundo a la manera de un observador meditativo, sino que lanzaba la refriega y prodigaba vigorosos mandobles para defender los que consideraba como lo único justo y posible" (p. 43).

No obstante, y a pesar de ser descrito como un ser de personalidad contradictoria, problemática, ilusoria, utópica, enferma y salida de la realidad, a él debe reconocérsele su apasionado espíritu de lucha, inspirado solo por el amor, la ternura, capacidad de reflexión y admiración de la vida humana, representada en aquella raza para entonces desconocida del indio de América. Su vida estaba dominada por una idea en la que "no vale la pena vivir solo para ganarse el pan, la vida también debe tener un sentido, servir al desarrollo del hombre" (Fromm, 1994, pp. 115-116).

\section{Referencias}

Aristóteles. (1999). Acerca del alma. En Martínez Tomas C. (Trad.). Madrid: Gredos.

Beuchot, M. (1994). Los fundamentos de los derechos humanos en fray Bartolomé de las Casas. España: Ánthropos.

Borges, P. (1990). Quién era Bartolomé de las Casas. Madrid: Rialp.

Borges, P. (1992). Historia de la Iglesia en Hispanoamérica y Filipinas (siglos XV-XIX): aspectos generales (Vol. I, pp. 33-34). Madrid: Biblioteca de Autores Cristianos.

Cabada, M. (1994). Querer o no querer vivir. El debate entre Schopenhauer, Feuerbach, Wagner y Nietzsche sobre el sentido de la existencia humana. Barcelona: Herder.

Castro, M. (1994). Querer o no querer vivir. Barcelona: Herber.

Coccia, E. (2011). La vida sensible. Buenos Aires: Marea.

De Las Casas, B. (1987). Brevísima relación de la destrucción de las Indias. Madrid: Ediciones Cátedra.

Dilthey, W. (1995). Teoría de las concepciones del mundo. En J. Marías. (Trad.). Barcelona: Altaya.

Enciclopedia de la Religión Católica. (1952). (Tomo II). Barcelona: Dalmau y Joven. 
Enzensberger, H. (1987). Bartolomé de las Casas: una retrospectiva al futuro. México: Universidad Nacional Autónoma de México.

Freide, J. (1978). Bartolomé de las Casas 1485-1566: su lucha contra la opresión. Medellín: Siglo XXI.

Galmez, L. (1989) Bartolomé de las Casas el hombre y el apóstol. Revista Documentos para el diálogo, 22, 9-31.

Fromm, E. (1994). El amor a la vida. En E. Prieto (Trad.). Barcelona: Paidós S.A.

Genevieve, D. (1992). Los mitos platónicos de 1992. Barcelona: Labor, S.A.

Hanke, L. (1965). Bartolomé de las Casas. Bogotá: Tercer Mundo.

Institutum Patristicum Augustinianum. (1998). Diccionario patrístico de la antigüedad cristiana (Tomo II). Salamanca: Sígueme.

Kierkegaard, S. (1997). Migajas filosóficas o un poco de filosofía. Madrid: Trota.

Losada, A. (1970). Fray Bartolomé de las Casas a la luz de la moderna historia critica. España: Tecnos S.A.

Menéndez, P. (1963). El padre Las Casas: su doble personalidad. Madrid: Espasa-Calpe.

Olaizola, J. (1991). Bartolomé de las Casas, crónicas de un sueño. Barcelona: Planeta.

Real Academia de la Lengua. (2001) Diccionario esencial. Madrid: Espasa.

Seneca. (1992). De la brevedad de la vida. En L. Riber (Trad.). Madrid: Aguilar.

Sarmiento, A. (1988). De las leyes de Indias: antología de la recopilación de 1681. México: Secretaría de Educación Pública.

Sebastián, A. (2009). De Leyes de Burgos. Recuperado de: http://www.laguia2000. com/el-mundo/leyes-de-burgos.

Wahl, J. (1956). Las filosofías de la existencia. En A. Sanvisens. (Trad.). Barcelona: Vergara. 